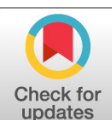

\title{
Emergence of mcr-1 in Raoultella ornithinolytica and Escherichia coli Isolates from Retail Vegetables in China
}

\author{
Juan Luo, ${ }^{a}$ Xu Yao, a Luchao Lv, ${ }^{\text {a }}$ Yohei Doi, ${ }^{b}$ Xiuyu Huang, ${ }^{a}$ Sicheng Huang, ${ }^{\text {a }}$ \\ Jian-Hua Liua \\ College of Veterinary Medicine, Guangdong Provincial Key Laboratory of Veterinary Pharmaceutics \\ Development and Safety Evaluation, South China Agricultural University, Guangzhou, Guangdong, Chinaa; \\ Division of Infectious Diseases, University of Pittsburgh Medical Center, Pittsburgh, Pennsylvania, USA ${ }^{b}$
}

ABSTRACT The presence of mcr-1 among Enterobacteriaceae isolates collected from retail vegetables in China between 2015 and 2016 was investigated. Two Raoultella ornithinolytica and seven Escherichia coli strains recovered from lettuce and tomato samples were identified as MCR-1-producers. Similar to isolates from animals and humans, the $m c r-1$ gene was located on the IncHI2/ST3, Incl2, or IncX4 plasmids. The presence of MCR-1-producing organisms in ready-to-eat food samples represents a serious risk for human health.

KEYWORDS Escherichia coli, Raoultella ornithinolytica, mcr-1, plasmid, vegetable

Clistin is generally considered the last resort antibiotic for treating infections caused by extensively drug-resistant (XDR) Enterobacteriaceae (1, 2). The emergence of the plasmid-mediated colistin resistance gene, $\mathrm{mcr}-1$, has therefore gained a lot of attention (3). This gene has spread worldwide and been detected in several genera of Enterobacteriaceae (Escherichia, Klebsiella, Salmonella, Shigella, Enterobacter, Kluyvera, and Citrobacter) (4-6). Although MCR-1-producing bacteria are mainly detected in animal sources, environmental samples (river water and sewage) with strains harboring mcr-1 have also been reported (4-9). Vegetables, which might be contaminated with bacteria via sewage irrigation, have also been reported to carry bacteria harboring mcr-1 (8). We investigated the occurrence of $\mathrm{mcr}-1$ in Enterobacteriaceae isolated from retail vegetables in Guangzhou, China.

Between May 2015 and August 2016, 916 fresh vegetable samples (239 lettuce heads, 218 tomatoes, 176 carrots, 264 cucumbers, and 19 bean sprouts) were collected from 41 farmers' markets and 12 supermarkets in Guangzhou, China. Chromogenic Brilliance extended-spectrum $\beta$-lactamase (ESBL) agar plates (CHROMagar Microbiology, Paris, France) were used for isolation of ESBL producers which were identified by matrix-assisted laser desorption ionization-time of flight mass spectrometry (MALDITOF MS) (Shimadzu, Japan) and some were confirmed by $16 \mathrm{~S}$ rRNA sequencing. A total of 244 ESBL-producing Enterobacteriaceae isolates (175 Klebsiella pneumoniae, 23 E. coli, and 46 others) were recovered from 216 samples. The MICs of 10 antibiotics were determined by an agar dilution or a broth microdilution method. The presence of $\mathrm{mcr}-1$ and $m c r-2$ in this strain collection was determined by PCR and sequencing using the primers described previously $(1,10)$. Our results showed that six of the $244(2.5 \%)$ ESBL-producing isolates (four E. coli and two Raoultella ornithinolytica) were positive for mcr-1 (Table 1). The prevalence of $m c r-1$ in the 23 ESBL-producing $E$. coli isolates was 17.4\%. Four ESBL producers (one Klebsiella pneumonia isolate and three Enterobacter species isolates) were resistant to colistin but were negative for $\mathrm{mcr}-1$ and $\mathrm{mcr}-2$.

In addition, 26 E. coli isolates were obtained from the 916 samples by using
Received 31 May 2017 Returned for modification 19 June 2017 Accepted 28 June 2017

Accepted manuscript posted online 24 July 2017

Citation Luo J, Yao X, Lv L, Doi Y, Huang X, Huang S, Liu J-H. 2017. Emergence of $\mathrm{mcr}-1$ in Raoultella ornithinolytica and Escherichia coli isolates from retail vegetables in China. Antimicrob Agents Chemother 61:e01139-17. https://doi.org/10.1128/AAC.01139-17. Copyright $\odot 2017$ American Society for Microbiology. All Rights Reserved. Address correspondence to Jian-Hua Liu, jhliu@scau.edu.cn. 


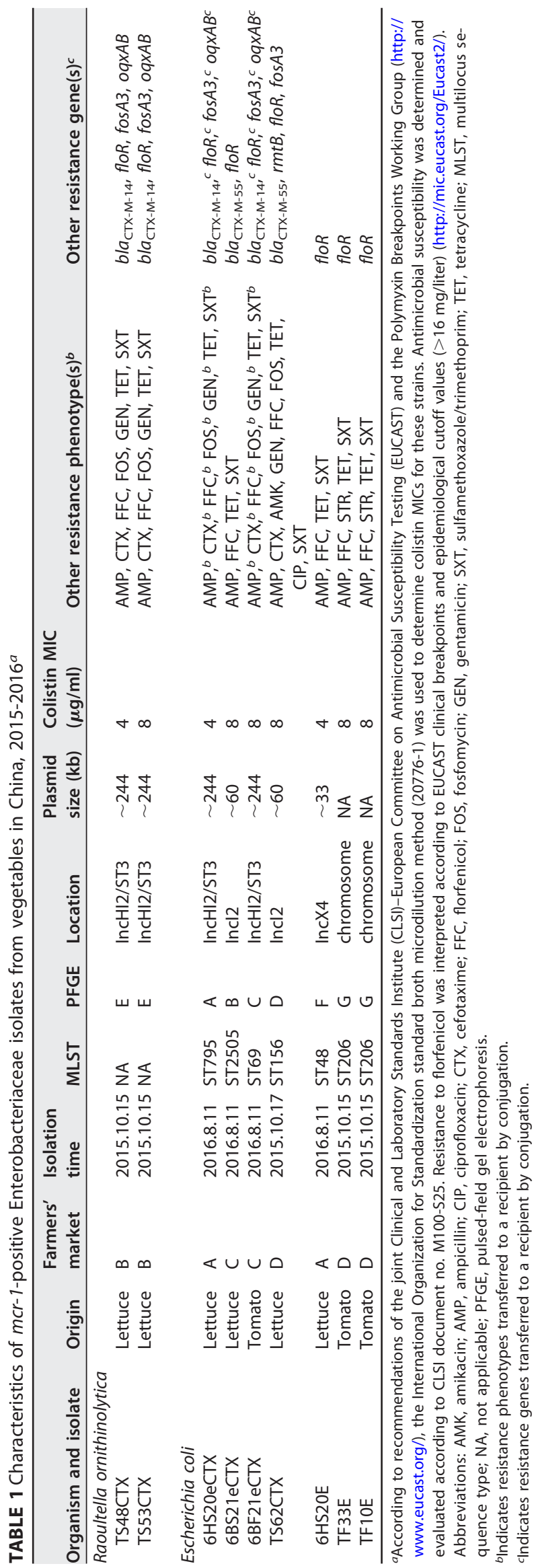


MacConkey agar plates without antibiotics and were identified by biochemical methods and $16 \mathrm{~S}$ rRNA sequencing. Three (11.5\%) of them were positive for $\mathrm{mcr}-1$.

All nine $\mathrm{mcr}$-1-carrying isolates showed resistance to colistin and florfenicol (Table 1). In addition, 6 and 5 isolates exhibited resistance to cefotaxime and fosfomycin, respectively. By PCR, all $m c r-1$-positive isolates carried the floR gene, and 6, 5, and 4 of them carried the bla $a_{\mathrm{CTX}-\mathrm{M}}\left(4 b / a_{\mathrm{CTX}-\mathrm{M}-14}\right.$ and $\left.2 b / a_{\mathrm{CTX}-\mathrm{M}-55}\right)$, fos $A 3$, and oqxAB genes, respectively (Table 1 ).

The clonal relatedness among the mcr-1-positive isolates was determined using pulsed-field gel electrophoresis (PFGE) and multilocus sequence type (MLST) analysis (the second only for E. coli) (http://www.warwick.ac.uk/mlst/). Six of the $\mathrm{mcr}$-1-positive $E$. coli isolates were clonally unrelated, while two $E$. coli and the two R. ornithinolytica strains were related (Table 1). PFGE after S1 nuclease digestion and hybridization revealed that $\mathrm{mcr}-1$ was located on 30 - to $250-\mathrm{kb}$ plasmids in 7 isolates (five $E$. coli and $2 R$. ornithinolytica), but was located on the chromosome in the two ST206 E. coli strains (Table 1). A conjugation experiment using streptomycin-resistant E. coli C600 as recipient and selection with colistin $(2 \mu \mathrm{g} / \mathrm{ml})$ and streptomycin $(3000 \mu \mathrm{g} / \mathrm{ml})$ yielded 5 transconjugants from five of the seven $m c r-1$-positive $E$. coli isolates. In 2 transconjugants, fos $A 3$, floR, and bla $a_{\mathrm{CTX}-\mathrm{M}-14}$ were cotransferred with $m c r-1$. The replicon types of the $m c r-1$-harboring plasmids were determined using the protocol provided in the Plasmid MLST Database (http://pubmlst.org/plasmid/); two IncHI2/ST3, two Incl2, and one IncX4 plasmids were identified (Table 1). The genetic context of mcr-1 was investigated using primers: CLR3-F (CGAAGCACCAAGACATCA) and CLR3-R (CCACAAG AACAAACGGACT); Mhp-F (TTGCCAGATTTGCTACTGT) and ISAp-R (TTCTCGCTCGTTTAT TGTA). ISAp/1 was located upstream of $m c r-1$ in all the isolates except $E$. coli TS62CTX and 6HS20E. Three isolates (6BS21eCTX, TF33E, and TF10E) also carried ISAp/1 downstream of $m c r-1$.

Recent studies have implied that fresh produce might be a possible route for the spread of resistance genes in the community $(8,11)$. This study documented the presence of $\mathrm{mcr}-1$ in Enterobacteriaceae isolates from lettuce and tomato. Although the occurrence of $\mathrm{mcr}-1$ in isolates from vegetables was lower than that in isolates from food animals and animal foods in China (3), the presence of MCR-1-producing bacteria in vegetables represents a threat to human health, as fresh vegetables such as tomato and lettuce are often consumed raw. Of note, the plasmids (IncHI2/ST3, IncX4, and Incl2) accounting for the spread of $\mathrm{mcr}-1$ found in this study were similar to those found in food animals from China $(5,12-14)$ and all $m c r-1$-positive isolates carried the florfenicol (an antimicrobial agent used only in animals) resistance gene floR. Vegetables are often in direct contact with the soil and water, which are known to be important reservoirs of antimicrobial resistance genes shared between animals, humans, and the environment (15). In addition, vegetables might be fertilized with manure and wastewater from antimicrobial-treated livestock. Thus, the MCR-1producers found in vegetables might have originated from animals.

Here, we reported the emergence of $m c r-1$ and fos $A 3$ in $R$. ornithinolytica, belonging to a genus in Enterobacteriaceae that is closely related to Klebsiella (16). $R$. ornithinolytica is usually found in aquatic, soil, and botanical environments. It is also an unusual pathogen associated with community-acquired infections. However, cases of R. ornithinolytica infection might have been underrecognized due to its misidentification as a Klebsiella species in clinical laboratories that use conventional phenotypic methods (17). Recently, the number of reported $R$. ornithinolytica infections in humans has grown, probably due to the introduction of mass spectrometry and the use of molecular identification techniques in clinical microbiology laboratories $(16,17)$. Carbapenem resistance genes have been detected in $R$. ornithinolytica in China (18); thus, the presence of mcr-1 in $R$. ornithinolytica, as well as fosA3 and bla $a_{\mathrm{CTX}-\mathrm{M}-14}$, will lead to the emergence of multidrug-resistant $R$. ornithinolytica strains.

In summary, the results of this study indicated that fresh vegetables constituted a possible route for the spread of MCR-1-producing Enterobacteriaceae species. The presence of MCR-1-producing organisms in the food supply and ready-to-eat foods is 
alarming and represents a serious risk for human health. To improve food safety and consumer health, appropriate measures such as proper disposal of animal excrement before use as fertilizers and improvement of the quality of irrigation water need to be taken. Further studies are required for evaluating the prevalence of antimicrobial resistance genes in vegetables in China and other countries.

\section{ACKNOWLEDGMENTS}

This work, including the efforts of Jian-Hua Liu, was supported in part by grants from the National Natural Science Foundation of China (no. 31625026 and no. 81661138002) and the National Key Basic Research Program of China (no. 2013CB127200).

The authors have no conflicts to declare.

\section{REFERENCES}

1. Viehman JA, Nguyen MH, Doi Y. 2014. Treatment options for carbapenem-resistant and extensively drug-resistant Acinetobacter baumannii infections. Drugs 74(12):1315-1333. https://doi.org/10.1007/ s40265-014-0267-8.

2. Magiorakos AP, Srinivasan A, Carey RB, Carmeli Y, Falagas ME, Giske CG, Harbarth S, Hindler JF, Kahlmeter G, Olsson-Liljequist B, Paterson DL, Rice LB, Stelling J, Struelens MJ, Vatopoulos A, Weber JT, Monnet DL. 2012. Multidrug-resistant, extensively drug-resistant and pandrugresistant bacteria: an international expert proposal for interim standard definitions for acquired resistance. Clin Microbiol Infect 18(3):268-281. https://doi.org/10.1111/j.1469-0691.2011.03570.x.

3. Liu YY, Wang Y, Walsh TR, Yi LX, Zhang R, Spencer J, Doi Y, Tian G, Dong B, Huang X, Yu LF, Gu D, Ren H, Chen X, Lv L, He D, Zhou H, Liang Z, Liu $\mathrm{JH}$, Shen J. 2016. Emergence of plasmid-mediated colistin resistance mechanism MCR-1 in animals and human beings in China: a microbiological and molecular biological study. Lancet Infect Dis 16:161-168. https://doi.org/10.1016/S1473-3099(15)00424-7.

4. Schwarz S, Johnson AP. 2016. Transferable resistance to colistin: a new but old threat. J Antimicrob Chemother 71(8):2066-2070. https://doi .org/10.1093/jac/dkw274.

5. Poirel L, Jayol A, Nordmann P. 2017. Polymyxins: Antibacterial activity, susceptibility testing, and resistance mechanisms encoded by plasmids or chromosomes. Clin Microbiol Rev 30:557-596. https://doi.org/10 .1128/CMR.00064-16.

6. Sennati S, Di Pilato V, Riccobono E, Di Maggio T, Villagran AL, Pallecchi L, Bartoloni A, Rossolini GM, Giani T. 2017. Citrobacter braakii carrying plasmid-borne $\mathrm{mcr}-1$ colistin resistance gene from ready-to-eat food from a market in the Chaco region of Bolivia. J Antimicrob Chemother 72:2127-2129. https://doi.org/10.1093/jac/dkx078.

7. Zhao F, Zong Z. 2016. Kluyvera ascorbata strain from hospital sewage carrying the $\mathrm{mcr}-1$ colistin resistance gene. Antimicrob Agents Chemother 60:7498-7501. https://doi.org/10.1128/AAC.01165-16.

8. Zurfuh K, Poirel L, Nordmann $P$, Nüesch-Inderbinen $M$, Hächler $H_{\text {, }}$ Stephan R. 2016. Occurrence of the plasmid-borne $\mathrm{mcr}-1$ colistin resistance gene in extended-spectrum- $\beta$-lactamase-producing Enterobacteriaceae in river water and imported vegetable samples in Switzerland. Antimicrob Agents Chemother 60:2594-2595. https://doi.org/10.1128/ AAC.00066-16.

9. Ovejero CM, Delgado-Blas JF, Calero-Caceres W, Muniesa M, GonzalezZorn B. 2017. Spread of mcr-1-carrying Enterobacteriaceae in sewage water from Spain. J Antimicrob Chemother 72:1050-1053. https://doi .org/10.1093/jac/dkw533.

10. Xavier BB, Lammens $C$, Ruhal R, Kumar-Singh S, Butaye P, Goossens $H$, Malhotra-Kumar S. 2016. Identification of a novel plasmid-mediated colistin-resistance gene, $\mathrm{mcr}$-2, in Escherichia coli, Belgium, June 2016. Euro Surveill 21(27):pii=22525. http://www.eurosurveillance.org/View Article.aspx?Articleld $=22525$.

11. Zurfluh $K$, Nüesch-Inderbinen $M$, Morach $M$, Zihler Berner $A$, Hächler $H_{\text {, }}$ Stephan R. 2015. Extended-spectrum- $\beta$-lactamase-producing Enterobacteriaceae isolated from vegetables imported from the Dominican Republic, India, Thailand, and Vietnam. Appl Environ Microbiol 81(9):3115-3120. https://doi.org/10.1128/AEM.00258-15.

12. Li R, Xie M, Zhang J, Yang Z, Liu L, Liu X, Zheng Z, Chan EW, Chen S. 2017. Genetic characterization of $\mathrm{mcr}$-1-bearing plasmids to depict molecular mechanisms underlying dissemination of the colistin resistance determinant. J Antimicrob Chemother 72:393-401. https://doi.org/10.1093/ jac/dkw411.

13. Liu BT, Song FJ, Zou M, Zhang QD, Shan H. 2017. High incidence of Escherichia coli strains coharboring $m c r-1$ and $b / a_{\mathrm{NDM}}$ from chickens. Antimicrob Agents Chemother 61:e02347-16. https://doi.org/10.1128/ AAC.02347-16.

14. Zhi C, Lv L, Yu LF, Doi Y, Liu JH. 2016. Dissemination of the $m c r-1$ colistin resistance gene. Lancet Infect Dis 16:292-293. https://doi.org/10.1016/ S1473-3099(16)00063-3.

15. Forsberg KJ, Reyes A, Wang B, Selleck EM, Sommer MO, Dantas G. 2012. The shared antibiotic resistome of soil bacteria and human pathogens. Science 337:1107-1111. https://doi.org/10.1126/science.1220761.

16. Ponce-Alonso M, Rodríguez-Rojas L, Del Campo R, Cantón R, Morosini MI. 2016. Comparison of different methods for identification of species of the genus Raoultella: report of 11 cases of Raoultella causing bacteraemia and literature review. Clin Microbiol Infect 22:252-257. https:// doi.org/10.1016/j.cmi.2015.10.035.

17. Seng $P$, Boushab BM, Romain F, Gouriet F, Bruder N, Martin C, Paganelli F, Bernit E, Le Treut YP, Thomas P, Papazian L, Raoult D, Stein A. 2016. Emerging role of Raoultella ornithinolytica in human infections: a series of cases and review of the literature. Int J Infect Dis 45:65-71. https:// doi.org/10.1016/j.ijid.2016.02.014.

18. Sun $P, B i$, Nilsson $M$, Zheng B, Berglund B, Stålsby Lundborg C, Börjesson S, Li X, Chen B, Yin H, Nilsson LE. 2017. Occurrence of bla $a_{\mathrm{KPC}-2}$ bla $a_{\mathrm{CTX}-\mathrm{M}}$ and $\mathrm{mcr}-1$ in Enterobacteriaceae from well water in rural China. Antimicrob Agents Chemother 61:e02569-16. 